\title{
Eğitim, Sağlık ve Teknoloji Düzeyinin Ekonomik Büyüme Üzerindeki Etkisi: ARDL Sınır Test Yaklaşımı
}

Harun YAKIŞIK

Ahmet ÇETIN

haruny@karatekin.edu.tr

akcetin@karatekin.edu.tr

\section{The Impacts of Education, Health and Level of Technology on Economic Growth: ARDL Bounds Test Approach}

\begin{abstract}
In this study, Augmented Solow Model has been estimated for the period of 1980-2012 in Turkey by using ARDL bounds test method. In the Augmented Solow Model, the level of technology was included as an independent variable into the model and proxied by number of patents. Human capital was proxied by two different variables; education and health. Average expectancy of life was used as a health variable and the schooling ratio of secondary and higher education were used as an education variable. With respect to findings, there are significant and positive impacts of patent, average life of expectancy, and secondary schooling ratio on growth while there is no impact of higher education schooling ratio.
\end{abstract}

Keywords : Human Capital, Economic Growth.

JEL Classification Codes : $\mathrm{O} 10, \mathrm{O} 15, \mathrm{O} 40$.

\section{Özet}

$\mathrm{Bu}$ çalışmada Genişletilmiş Solow Modeli, ARDL yöntemi kullanılarak Türkiye'nin 1980-2012 dönemi verileri ile tahmin edilmiştir. Genişletilmiş Solow Modelinde teknoloji düzeyi bağımsız değişken olarak modele alınmış ve patent sayısıyla temsil edilmiştir. Beşeri sermaye, eğitim ve sağlık olmak üzere iki farklı değişkenle temsil edilmiştir. Sağlık göstergesi olarak ortalama yaşam süresi kullanılırken eğitim göstergesi olarak orta ve yükseköğretim okullaşma oranları tercih edilmiştir. Elde edilen bulgulara göre patent, ortalama yaşam süresi ve orta öğretim okullaşma oranının büyüme üzerinde anlamlı ve pozitif etkisi varken yükseköğretimin etkisi yoktur. 
Harun YAKIŞIK \& Ahmet ÇETIN 


\section{Giriş}

Ekonomik büyüme, gerek gelişmiş ülkelerin gerekse gelişmekte olan ülkelerin önemli gündemlerinden birini oluşturmaktadır. Gelişmekte olan ülkelerde fiziksel sermaye birikimi öne çıkarken, gelişmiş ülkelerde beşeri sermaye odaklı büyüme stratejileri tartışılmaktadır. Ekonomik büyüme, gelişmekte olan ülkeler için kalkınmanın finansmanı, gelişmiş ülkeler içinse refahın sürdürülmesi anlamına gelmektedir. Bu nedenle büyümenin kaynakları hem teorik düzey hem de ampirik düzeyde yapılan birçok çalışmayla tespit edilmeye çalışılmaktadır. Teorik çalışmalarda sürdürülebilir büyümenin kaynakları sorgulanırken ampirik çalışmalarda büyüme üzerinde hangi değişkenlerin etkin olduğu öne çıkmaktadır.

Büyüme alanında yapılan ilk çalı̧̧malarda emek ve sermaye modellenirken yakın dönem çalışmalarında teknoloji ve beşeri sermaye ağırlık kazanmaktadır. Romer (1986) teknolojiyi içselleştirirken Mankiw, Romer ve Weil (1992) Solow modeline beşeri sermayeyi ekleyerek genişletmiştir. Mankiw vd. (1992) Solow modelinde sermaye kavramını genişleterek fiziki sermaye yanında beşeri sermayenin de ekonomik büyümeye doğrudan katkı yapacağını ileri sürmüştür. Mankiw vd. (1992) geliştirdikleri model (MRW) bulgularına göre, ülkeler arasında giderek açılan kişi başına gelir farklılığının \%80'lere varan kısmının ülkelerin beşeri sermaye farklılıklarıyla açıklandığı sonucuna ulaşmışlardır. Dolayısıyla Solow modelinin temel bulgusu olan sermayenin azalan getiri durumu, beşeri sermayeyi içeren MRW modelinde artan getir durumuna dönüşmüş ve böylece büyümenin sürekli olabileceği ileri sürülmüştür (Sala-i Martin, 1990).

Uzun dönemde sürdürülebilir büyümeyi gerçekleştiren dinamiğin beşeri sermaye, beşeri sermayeyi etkileyen faktörlerin ise eğitim ve sağlık harcamaları olduğu yakın dönem büyüme çalışmalarında vurgulanmaktadır. Bu çalışmalarda, artan sağlık harcamalarıyla bireylerin sağlıklı yaşam süresinin (Kelly, 1997: 64) ve emek faktörünün ekonomik büyümeye pozitif katkısının artacağı vurgulanmaktadır (Glomm ve Ravikumar, 1997: 201).

Bu çalışmanın amacı, Menkiw vd. (1992) modelini esas alarak beşeri sermaye (eğitim ve sağlik) yanında teknolojik gelişmenin büyüme üzerindeki etkisini Türkiye'nin 1980-2012 döneminde ARDL yöntemi kullanarak tespit etmektir. Çalışmada beşeri sermaye, eğitim ve sağlık olmak üzere iki farklı değişkenle temsil edilmiştir. Sağlık değişkeni olarak ortalama yaşam süresi kullanılırken, eğitim değişkeni ise orta-öğretim ve yükseköğretime kayıtlı öğrenci yüzdeleri olarak iki farklı kademede temsil edilmiştir. Teknoloji düzeyini temsilen patent sayıları tercih edilmiştir.

$\mathrm{Bu}$ çalışmanın ikinci kısmında teknoloji ve beşeri sermaye kullanan literatür incelenerek, özellikle beşeri sermayeyi eğitim ve sağlık değişkenleriyle analiz eden 
çalışmalar öne çıkartılmıştır. Kullanılan model ve yöntem üçüncü kısımda yer alırken, dördüncü kısımda verilerle ampirik sonuçlar raporlanmıştır. Ampirik bulgular beşinci bölümde değerlendirilmiştir. Son bölümde ise sonuca yer verilmiştir.

\section{Literatür Özeti}

Büyüme modelinin ilk sistematik çalışmalarının Harrod (1939) ve Domar (1946) tarafından geliştirildiği bilinmektedir. Harrod-Domar modeli uzun dönemde sermaye ve emek arasında ikamenin mümkün olmadığı varsayımına dayanmakta ve bu nedenle ekonometrik modellerin gelişmesine katkısının zayıf kaldığı bilinmektedir. Daha sonra Neo-Klasik büyüme modeli olarak da adlandırılan Solow (1956) ve Swan (1956) modeli geliştirilmiş ve bu modelde üretim faktörleri arasında tam ikamenin olduğu ve sermayenin azalan getiri ilkesinin geçerliliği kabul edilmiştir. Solow (1956)'un bu modelde ortaya koyduğu en önemli sonuç, uzun dönemde ülkelerin kararlı büyümeye erişeceği ve büyümenin, teknolojik büyüme hızı ile nüfus artış hızı tarafından dışsal olarak belirlendiğidir. Böylece Solow modeli dışsal faktörler tarafından belirlenen bir büyüme süreci ortaya koymaktadır. İçsel büyüme modelleri ise Solow modelinin cevaplayamadığı büyümenin dışsal kaynağını içselleştirerek açıklamaya çalışmaktadır. İçsel büyüme modelinde beşeri sermaye modele eklenerek sermayenin azalan getirisi yerine artan getiri ilkesiyle çalı̧̧abileceği ve böylece büyümenin azalmadan devam edebileceği ortaya konulmuştur.

İçsel büyüme modelinin öncülerinden Romer (1986) ve Lucas (1988)'1n çalışmalarında teknoloji değişkeni modele alınmış ve ülkelerin teknolojiyi kendi içsel ekonomik dinamikleri içerisinde üretecekleri kabul edilmiştir. Modelde ülkelerin beşeri sermaye birikimleri ve Ar-Ge çalışmaları sonucu yaratacakları yeniliklerin, büyümeyi gerçekleştireceği ve sürekli kılacağı ortaya konulmuştur. Dolayısıyla içsel büyüme modelleri ekonomik büyümenin gerçekleşmesinde Neo-Klasiklerin keşfedemediği gerçeği ortaya koymaktadır. Romer (1986) modelde büyümeyi gerçekleştirecek ve sürekli kılacak dinamiğin Ar-Ge faaliyetleri sonucu ortaya çıacak yenilikler olduğunu ve bu yenilikleri de ortaya çıkaracak dinamiğin nitelikli beşeri sermaye olacağını vurgulamıştır.

Mankiw vd. (1992) yaptıkları çalışmada eğitim düzeyindeki artışın emek faktörünün verimini artırarak azalan getiri yerine artan getiri haline dönüşeceği ve üretimde dinamik yapının sağlanacağını ortaya koymaktadır. Lucas (1998), emek faktörünün elde ettiği eğitim ve verimlilik artışının, artan getiri yaratacağını, ayrıca ülkenin üretim gücünün dinamik hale getireceğini ortaya koymaktadır. Dolayısıyla, eğitim ve verimlilik etkileşimi uzun dönemde ekonomik büyümede sürekliliğin gerçekleşeceğini vurgulamaktadır. 
Beşeri sermayenin en önemli bileşenlerinden biri eğitimdir. Beşeri sermayeyi temsil eden eğitimin, emek faktörünün beceri, üretkenlik, yenilikçilik ve teknoloji yaratma kapasitesini artırarak büyümeyi pozitif yönde etkileyeceği vurgulanmaktadır (Denison, 1962; Schultz, 1968; Becker, 1974). Bu nedenle beşeri sermaye ölçümlerinde yaygın olarak eğitimle ilgili değişkenler tercih edilmektedir. Beşeri sermaye değişkeni olarak emek faktörünün eğitim düzeyinin yükselmesi Neo-Klasik modelde oluşan azalan getiri sorununu ortadan kaldırdığı gibi artan getiri prensibine göre de çalışabileceğini ortaya koymaktadır (Romer, 1990; Grossman ve Helpman, 1991; Aghion ve Howitt, 1992). Genel olarak eğitim düzeyindeki yükselmenin büyümeyi pozitif yönde etkilediği literatürde güçlü şekilde vurgulanmaktadır (Barro ve Lee, 1998). Bununla birlikte, eğitim değişkeninin tüm ülkelerde ekonomik büyümeye aynı derecede katkı yaptığını söylemek güçtür. Ülkelerin farklı eğitim kalitelerine sahip olması, eğitimin etkisini de farklılaştırmaktadır. Eğitim kalitesi yüksek ülkelerde büyüme etkisinin de yüksek olduğu yapılan çalışmalarla tespit edilmiştir (Dünya Bankası, 1993; Hanushek ve Kimko, 2000). Bunun yanında ülkelerin farklı düzeylerde eğitim altyapısına ve eğitmen başına öğrenci sayılarına sahip olmaları, eğitimin kalitesini ve büyümeye etkisini de farklılaştırmaktadır (Page, 1994; Schultz, 1996). Eğitimin büyüme üzerinde olumlu etkilerini tespit eden birçok çalışma yanında Krugman (1994), gelişmiş ülkelerin eğitim seviyelerinin ve ortalama okullaşma oranlarının yüksek olmasından dolayı eğitime yapılan yatırımların ekonomik büyümeyi düşürdügünü de tespit etmiştir. Türkiye özelinde beşeri sermaye ve büyüme arasında ilişkiyi inceleyen çalışmalara baktığımızda; eğitim ve ekonomik büyüme arasında olumlu bir ilişkinin olduğu ortaya konulmaktadır (Ergen, 1999: 21-56). Eğitim ve büyüme arasında olumlu etkinin uzun dönem de de devam edeceği ileri sürülmektedir (Çakmak ve Gümüş, 2005: 59-72). Diğer taraftan eğitim ve büyüme arasında nedensellik ilişkisini araştıran çalışmaların ise karşılıklı nedensellik ilişkisinin olduğunu ortaya koymaktadır (Kar ve Ağır, 2003; Beşkaya vd. 2003: 43-62).

Beşeri sermayenin bir diğer bileşeni sağlıktır. Beşeri sermayenin sağlığ kapsaması, üretim faktörlerinden biri olan emek faktörünün daha etkin sağlık hizmetleriyle daha üretken olacağı savına dayanmaktadır (Bloom and Canning, 2000). Bunun yanında etkin sağlık hizmetleri alan bireylerin daha nitelikli eğitim alma firsatlarının da olduğu vurgulanmaktadır. Literatürde sağlık-büyüme ilişkisini inceleyen çok sayıda çalışma bulunmaktadır. Bu konudaki yaygın görüş, etkin sağlık hizmetlerinin büyümeyi pozitif yönde etkilerken kötü sağlık koşullarının da emek verimliliğini düşürerek büyümeyi negatif yönde etkilediğidir (Arndt, 2006; Bloom ve Canning, 2000; Couderc ve Ventelou, 2005; McDonald ve Roberts, 2006). Cole and Neumayer (2006) sağlık koşulları çok kötü olan Sahra Altı Afrika ülkelerinde yaptığı çalışmasında kötü sağlık hizmetlerinin büyümeyi negatif yönde etkilediğini ortaya koymuştur.

Sağlık hizmetlerinin ölçülmesinde sağlığa yapılan harcamalar yanında ortalama yaşam süresi de kullanılmaktadır. Bu yaklaşım, etkin bir sağlık hizmetinin bireylerin 
yaşam süresini uzatacağı savına dayanmaktadır. Ömür boyu gelir hipotezine göre bireylerin ortalama yaşam süresinin artmasına paralel olarak tasarruf miktarları da artmaktadır. Artan tasarruf miktarları sermaye birikimini hızlandırmakta ve büyümeyi pozitif yönde etkilemektedir (Glomm ve Ravikumar, 1997). Bununla birlikte, ortalama yaşam süresinin artmasının büyümeye etkisi ülkenin gelir düzeyine göre değişiklik göstermektedir. Ortalama yaşam süresinin yükselmesi, düşük gelirli ülkelerde yüksek gelirli ülkelere göre büyüme performansını daha çok etkilemektedir (Bhargava, Jamison, Lawrance ve Murray, 2001). Bunun yanında yüksek gelirli ülkelerde sağlık harcamalarından ekonomik büyümeye doğru işleyen bir nedensellik, düşük ve orta gelirli ülkelerde ise ekonomik büyümeden sağlık harcamalarına doğru işleyen bir nedensellik bulgusu elde edilmiştir (Erdil ve Yetkiner, 2014-URL).

\section{Model ve Yöntem}

Solow (1956), yapmış olduğu çalışmasıyla büyüme alanında yeni bir yaklaşım geliştirmiştir. Cobb-Doglaus tipi üretim fonksiyonu kullanan Solow modelinde ölçeğe göre sabit getiri prensibi benimsenmiştir. Neoklasik model olarak da bilinen bu modelde en önemli varsayım sermayenin zamanla azalan getiriye sahip olduğu varsayımıdır. Sermaye artışıyla büyüme devam ederken ekonomi durağan duruma geldiğinde sermaye kaynaklı büyüme durmaktadır. Bu aşamadan sonra büyüme dışsal olarak belirlenen nüfus artış hızı ve teknolojik gelişme tarafından belirlenmektedir. Nüfus artış hızı ve teknolojik değişim dışsal kabul edildiğinden model aslında büyümenin kaynağını açıklamamaktadır.

Mankiw vd. (1992), neoklasik modelin açıklayamadığı ve dişsal kabul ettiği teknolojik gelişmeyi içselleştirmeye çalışmıştır. Mankiw vd. (1992) tarafından geliştirilen modelde beşeri sermaye yeni bir değişken olarak alınmıştır. Beşeri sermayenin bağımsız değişken olarak modele eklenmesiyle sermayenin azalan getirisinin önlenebileceği ve beşeri sermaye artışıla fiziksel sermayenin artan getiri prensibi doğrultusunda büyüme sürekliliğinin sağlanabileceği belirtilmiştir. Mankiw vd. (1992) yapmış oldukları katkılılarla, beşeri sermaye ile genişletilmiş Solow modelini elde etmişlerdir.

\subsection{Model}

Bu çalışmada, Mankiw vd. (1992)'in beşeri sermayeyi kapsayan genişletilmiş Solow modeli benimsenmiştir. Model denklem 1'de gösterilmektedir.

$$
Y_{t}=K_{t}^{G} \cdot H_{t}^{3} \cdot\left(A_{t} \cdot L_{n}\right)^{1-G-\beta}
$$

Denklem 1'de $Y_{t}$ çıktı miktarını, $K_{t}$ fiziksel sermaye miktarını, $H_{t}$ beşeri sermaye düzeyini, $L_{t}$ çalışan sayısını, $A_{t}$ teknoloji düzeyini, $\alpha, \beta$ ve $(1-\alpha-\beta)$ girdilerin esnekliklerini 
göstermektedir. Parametreler hakkındaki varsayımlar $0<\alpha<1,0<\beta<1$ ve $\alpha+\beta<1$ şeklindedir. Parametrelere yapılan sınırlamalarla ölçeğe göre sabit getiri prensibinin yanında yeniden üretilebilir faktörlerin azalan getiri ilkesine tabi olduğu vurgulanmıştır.

Geleneksel genişletilmiş Solow modelinde teknoloji düzeyini gösteren $A_{t}$, işgücünü gösteren $L_{t}$ ile ilişkilendirilmektedir. Denklem, 'çalışan başına' formunda yazılmak için eşitliğin her iki tarafı $A_{t} L_{t}$ 'ye bölünmektedir. Elde edilen yeni denklem versiyonunda $A_{t}$ ve $L_{t}$ değişkenleri diğer değişkenlerin içinde etkilerini göstermektedir. Bizim çalışmamızda eşitliğin iki tarafi sadece $L_{t}$ 'ye bölünerek teknoloji değişskeni $A_{t}$ 'nin modelde kalması sağlanmıştır. Böylece beşeri sermaye yanında teknoloji düzeyinin de büyüme üzerindeki etkisi ölçülebilecektir. Denklem 1'in her iki tarafı $L_{t}$ 'ye bölünürse denklem 2 elde edilir.

$y_{t}=k_{t}^{\alpha} \cdot h_{t}^{\beta} \cdot A_{t}^{1-\alpha-\beta}$

Denklem 2'de $y_{t}=\left(Y_{t} / L_{t}\right)$ çalışan başına üretim miktarını, $k_{t}=\left(K_{t} / L_{t}\right)$ çalışan başına fiziksel sermaye miktarını, $h_{t}=\left(H_{t} / L_{t}\right)$ çalışanların ortalama beşeri sermaye düzeyini göstermektedir. Denklem 2'nin doğal logaritması alınırsa denklem 3 elde edilir.

$$
\ln \left(y_{t}\right)=\alpha \ln \left(k_{t}\right)+\beta \ln \left(h_{t}\right)+(1-\alpha-\beta) \ln \left(A_{t}\right)
$$

Denklem 3'de çalışan başına çıktı miktarı, çalışan başına fiziksel sermaye miktarı, çalışanların beşeri sermaye düzeyi ve teknoloji düzeyi tarafından belirlenmektedir. Denklem 3 ekonometrik tekniklerle tahmin edilirken regresyon denklem formatına dönüştürülür. Regresyon denklemine dönüştürülürken denklem 3'e sabit terim (c) ve hata terimi $(\varepsilon)$ eklenerek denklem 4 elde edilir.

$$
\ln \left(y_{t}\right)=c+\alpha \ln \left(k_{t}\right)+\beta \ln \left(h_{t}\right)+(1-\alpha-\beta) \ln \left(A_{t}\right)+a_{t}
$$

Denklem 4'de çalışan başına sermaye miktarı, çalışanların beşeri sermaye düzeyi ve teknoloji düzeyi ile çalışan başına çıktı düzeyi arasında pozitif ilişki beklenmektedir. Başka bir ifadeyle tüm değişkenlerin katsayıları pozitif beklenmektedir.

\subsection{ARDL Sınır Test Yaklaşımı}

Model tahmin edilmeden önce değişkenlerin zaman serisi özelliklerinin belirlenmesi gerekmektedir. Bu nedenle serilerin durağanlık özellikleri incelenmelidir. Durağanlık testlerinde yaygın olarak birim kök testleri kullanılmaktadır. Bu çalışmada durağanlık özellikleri için Genişletilmiş Dickey Fuller (ADF) ve Phillips-Perron (PP) birim kök testleri kullanılmaktadır. 
Modeldeki değişkenler arasındaki uzun dönemli ilişki Pesaran ve Shin (1999) ve Pesaran, Shin ve Smith (2001) tarafından geliştirilen ARDL sınır test yaklaşımı ile incelenecektir. Değişkenler arasındaki uzun dönemli eşbütünleşme ilişkisinin varlığı ise Engle ve Granger (1987) ve Johansen ve Juselius (1990) tarafından geliştirilen alternatif yöntemlerle de test edilebilmektedir. Bu çalışmada ARDL yönteminin tercih edilmesinin nedeni, küçük gözlemli çalışmalarda ARDL yönteminin alternatiflerine göre daha etkin sonuçlar vermesidir.

Sınır test yaklaşımında değişkenler arasında uzun dönemli ilişkinin varlığ denklem 5 ile sinanmaktadır.

$\Delta l n y_{t}=a_{0}+\sum_{i=1}^{n} b_{i} \Delta l n y_{t-i}+\sum_{i=0}^{n} c_{i} \Delta \ln k_{t-i}+\sum_{i=0}^{n} d_{i} \Delta l n h_{t-i}+\sum_{i=0}^{n} e_{i} \Delta \ln A_{t-i}+\sigma_{1} \ln y_{t-1}+\sigma_{2} \ln k_{t-1}+\sigma_{3} l n h_{t-1}+\sigma_{3} \ln A_{t-1}+s_{t}$

Denklem 5'de $\Delta$ birinci fark işlemcisi, $\ln y_{t}$ çalışan başına reel gsyh değerinin doğal logaritmasını, $\ln k_{t}$ çalışan başına sermaye miktarının doğal logaritmasını, $\ln h_{t}$ ortalama beşeri sermaye düzeyinin doğal logaritmasını ve $\ln A_{t}$ teknoloji düzeyinin doğal logaritmasını göstermektedir. Değişkenler arasındaki uzun dönemli ilişkinin varlığına Peseran vd. (2001) tarafından hesaplanan F-test sonuçlarına göre karar verilir. Peseran vd (2001) ARDL modelindeki tüm değişkenlerin I(1) ve I(0) olduğunu varsayarak F-testi için alt ve üst sınırlar için kritik değerleri hesaplamıştır. Modelde hesaplanan F-test istatistiği üst-sınır kritik değerden büyükse eşbütünleşik ilişkinin varlığı, alt-sınır kritik değerden küçükse eşbütünleşik ilişkinin yokluğu ve alt-üst sınır kritik değerleri arasındaysa eşbütünleşik ilişkinin varlığı veya yokluğuna ARDL yöntemiyle karar verilemeyeceği sonucuna ulaşılır. Peseran vd. (2001) F-test kritik değerlerinin hesaplanmasında 500-1000 gözlem büyüklüğünü dikkate almışlardır. Narayan (2005) aynı kritik değerleri 30 ila 80 adet gözlem sayısı için hesaplamıştır. Bizim çalışmamız 32 gözlem içerdiğinden Narayan (2005) tarafından 32 gözlem büyüklüğü için hesaplanan kritik değerler kullanılmıştır.

Denklem 5 tahmin edilerek yapılan F-test istatistiğine göre uzun dönemli ilişkinin varlığı bulunduktan sonra denklem 6 ve denklem 7 tahminleri yapılarak değişkenler arasındaki uzun ve kısa dönemli katsayıları bulunur.

$$
\begin{aligned}
& i n y_{t}=\gamma_{0}+\sum_{t=1}^{p} \gamma_{1 i} l n y_{t-i}+\sum_{t=0}^{p} \gamma_{\mathrm{a} i} \ln k_{t-i}+\sum_{t=0}^{p} \gamma_{s i} \operatorname{lnh} h_{t-i}+\sum_{t=0}^{p} \gamma_{s i} \ln A_{t-i}+a_{t}
\end{aligned}
$$

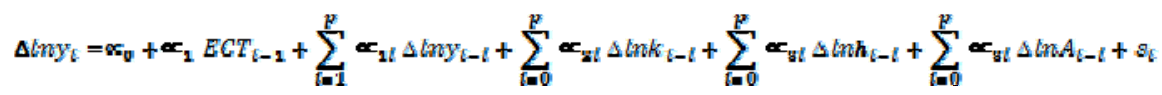


Eğitim, Sağlık ve Teknoloji Düzeyinin Ekonomik Büyüme Üzerindeki Etkisi: ARDL Sınır Test Yaklaşımı

\section{Veriler ve Ampirik Sonuçlar}

Çalışmada 1980-2012 dönemi yıllık veriler kullanılmıştır. Verilerin detaylı açıklaması Tablo: 1'de verilmiştir.

Tablo: 1

Verilerin Tanımlanması

\begin{tabular}{|l|l|}
\hline Çıtı düzeyi (Y) & Sabit fiyatlar kullanılarak GSYH ile ölçülmüştür. Dünya Bankasından alınmıştır. \\
\hline Sermaye Stoku (K) & $\begin{array}{l}\text { Saygılı, Cihan ve Yurtoğlu (2005)'nun 1972-2003 yılları için yapmış oldukları } \\
\text { sermaye stok hesaplaması esas alınarak, sermaye stok, 2012 yılına kadar yazarlar } \\
\text { tarafından hesaplanmıştır. Hesaplamada sermaye aşınması Saygılı vd. (2005) } \\
\text { çalışmasında 1980-2003 yıllarındaki aşınmaların yıllık ortalaması (0,043163) } \\
\text { alınmış ve 1979 yılı sermaye stokundan aşınma düşülerek ve sermaye oluşumu } \\
\text { eklenerek hesaplanma 2012 yılına kadar uzatılmıştır. }\end{array}$ \\
\hline Kalkınma Bakanlığı ve TÜIK verilerinden toplanmıştır. \\
\hline İstihdam (L) & $\begin{array}{l}\text { Teknoloji düzeyi için yerleşiklerin patent sayıları alınmıştır. Dünya Bankasından } \\
\text { alınmıştır. }\end{array}$ \\
\hline Teknoloji (PATENT) & $\begin{array}{l}\text { Beşeri sermaye sağlık göstergesi olarak ortalama yaşam süresi alınmıştır. Dünya } \\
\text { Bankasından alınmıştır. }\end{array}$ \\
\hline Beşeri Sermaye (YASAM) & $\begin{array}{l}\text { Beşeri sermaye eğitim göstergesi olarak orta öğretim (lise) düzeyindeki kayıtlı } \\
\text { öğrenci yüzdesi alınmışır. Dünya Bankasından alınmıştır. }\end{array}$ \\
\hline Beşeri Sermaye (ORTA) & $\begin{array}{l}\text { Beşeri sermaye eğitim göstergesi olarak yükseköğretim düzeyindeki kayıtlı } \\
\text { öğrenci yüzdesi alınmıştır. Dünya Bankasından alınmıştır. }\end{array}$ \\
\hline Beşeri Sermaye (YUKSEK)
\end{tabular}

Tablo: 2

ADF ve PP Birim Kök Test Sonuçları

\begin{tabular}{|c|c|c|c|c|}
\hline & \multicolumn{2}{|c|}{$\mathrm{ADF}$} & \multicolumn{2}{|c|}{$\mathrm{PP}$} \\
\hline & Sabit & Trend & Sabit & Trend \\
\hline $\ln (y)$ & \begin{tabular}{|l|}
-1.231095 \\
\end{tabular} & -3.198041 & -1.269978 & -3.174759 \\
\hline $\ln (\mathrm{k})$ & -1.815584 & 0.245656 & -1.777135 & 0.240701 \\
\hline $\ln$ (patent) & 2.752018 & -0.252403 & 3.419339 & 0.116135 \\
\hline $\ln \left({\text { yasam })^{*}}^{*}\right.$ & -1.747172 & 4.965723 & -4.517514 & 0.791179 \\
\hline $\ln$ (orta) & -1.339706 & -0.722347 & -1.292103 & -0.722347 \\
\hline $\ln$ (yüksek) & 0.483897 & -1.831273 & 0.483897 & -2.208668 \\
\hline$\Delta \ln (\mathrm{y})$ & $-7.328616^{* * * *}$ & $-7.330594 * * *$ & $-7.328616^{* * *}$ & $-7.389718^{* * * *}$ \\
\hline$\Delta \ln (\mathrm{k})$ & $-4.675227^{* * *}$ & $-5.207940 * * *$ & $-4.675455^{* * *}$ & $-5.199795 * * *$ \\
\hline$\Delta \ln ($ patent $)$ & -1.255597 & $-5.103016 * * *$ & $-5.366956 * * *$ & $-8.300053 * * *$ \\
\hline$\Delta \ln$ (yasam) $^{*}$ & \begin{tabular}{|l|}
2.836795 \\
\end{tabular} & $-9.723157 * * *$ & -0.668612 & -1.557099 \\
\hline$\Delta \ln$ (orta) & \begin{tabular}{|l}
$-4.072355 * * *$ \\
\end{tabular} & $-4.304295 * * *$ & $-4.067908 * * *$ & $-4.232310^{* *}$ \\
\hline$\Delta \ln ($ yüksek $)$ & $-4.714484 * * *$ & $-4.604255 * * *$ & $-4.733307 * * *$ & $-4.600429 * * *$ \\
\hline
\end{tabular}

Değişkenlerin durağanlık özellikleri için ADF ve PP birim kök testleri tercih edilmiştir. Tablo: 2'de birim kök test sonuçları raporlanmıştır. Sonuçlara göre tüm değişkenlerin düzeyde durağan olmadıkları ama birinci farkları alındıklarında durağan hale 
geldikleri görülmektedir. ARDL yöntemi için değişkenlerin aynı derecede entegre olma zorunlulukları bulunmamaktadır. Buna rağmen kritik sınır değerleri serilerin I(1) ve I(0) değerleri için hesaplandığından tüm değişkenlerin düzeyde veya birinci farkta durağan olmaları gerekmektedir. Başka bir ifadeyle, serilerden herhangi biri ikinci veya daha yüksek düzeyde durağan hale geliyorlarsa alt-üst sınırlar için belirlenen kritik değerler geçerliliğini yitirmektedir.

Tablo: 3'de modeldeki değişkenler arasında eşbütünleşme ilişkisinin varlığ test edilmektedir. Denklem 6'da belirtilen model üç farklı versiyonda sınanmıştır. Beşeri sermaye, sağlık ve eğitim göstergesi olarak iki farklı alanda temsil edilmiştir. Beşeri sermaye göstergesi olarak sağlık seçildiğinde ortalama yaşam süresi temsili değişken olarak belirlenmiştir. Beşeri sermaye eğitim ile temsil edildiğinde iki kademede eğitim göstergesi kullanılmıştır. Orta öğretim ve yükseköğretim eğitim düzeyleri için temsili değişken olarak kullanılmıştır.

Tablo: 3

\section{Uzun Dönem Eşbütünleşme İlişkisinin Test Sonuçları}

\begin{tabular}{|c|c|c|c|}
\hline Modeller & F-istatistiği & Gecikme Uzunluğu & Eşbütünleşme İlişkisinin Varlığı (\%5) \\
\hline 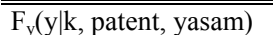 & 9.523340 & 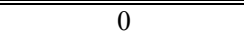 & VAR \\
\hline$\overline{\mathrm{F}_{\mathrm{y}}(\mathrm{y} \mid \mathrm{k}, \text { patent, orta })}$ & 6.174196 & 0 & VAR \\
\hline$\overline{F_{y}(y \mid k, ~ p a t e n t, ~ y u k s e k) ~}$ & 5.006954 & 1 & VAR \\
\hline
\end{tabular}

Tablo: 3'de beşeri sermayenin ortalama yaşam süresi, orta ve yükseköğretim düzeyi ile temsil edildiği üç model de Narayan (2005) tarafından hesaplan üst-sınır kritik değer olan 5,018 değerinden daha büyük F-istatistiğine sahip olduğundan uzun dönemli ilişkiye sahiptir.

Modellerin ampirik sonuçları Tablo: 4'de raporlanmıştır. Beşeri sermaye; Model 1 'de ortalama yaşam süresiyle, Model 2'de orta-öğretim okullaşma oranıyla ve Model 3'de yükseköğretim okullaşma oranıyla temsil edilmiştir. Model 1'de sağlık hizmetlerinin göstergesi olan ortalama yaşam süresi ve Model 2'de eğitim göstergesi olan orta-öğretim okullaşma oranı istatistiksel olarak anlamlı ve ekonomik büyümeyi pozitif yönde etkilediği, buna karşın Model 3'de eğitim göstergesi olan yükseköğretim okullaşma oranı istatistiksel olarak anlamsız bulunmuştur. 
Tablo: 4

ARDL Sonuçları

\begin{tabular}{|c|c|c|c|}
\hline & $\begin{array}{c}\text { Model 1: } \\
\text { Ortalama yaşam }\end{array}$ & $\begin{array}{c}\text { Model 2: } \\
\text { Orta-öğretim }\end{array}$ & $\begin{array}{c}\text { Model 3: } \\
\text { Yükseköğretim }\end{array}$ \\
\hline \multirow{2}{*}{ ARDL Spesifikasyonu } & $\mathrm{F}_{\mathrm{y}}(\mathrm{y} \mid \mathrm{k}$, patent, yasam $)$ & $\mathrm{F}_{\mathrm{y}}(\mathrm{y} \mid \mathrm{k}$, patent, orta $)$ & $\mathrm{F}_{\mathrm{y}}(\mathrm{y} \mid \mathrm{k}$, patent, yuksek) \\
\hline & $\operatorname{ARDL}(1,1,0,0)$ & $\operatorname{ARDL}(1,1,0,3)$ & $\operatorname{ARDL}(1,1,2,2)$ \\
\hline Sabit & $\begin{array}{l}-6.3141 \\
-1.7271\end{array}$ & $\begin{array}{l}5.2258 \\
7.9277\end{array}$ & $\begin{array}{l}3.2205 \\
2.2233\end{array}$ \\
\hline $\ln \left(\mathrm{k}_{\mathrm{t}}\right)$ & $\begin{array}{l}-0.28566 \\
-0.96583\end{array}$ & $\begin{array}{c}0.046741 \\
0.32042\end{array}$ & $\begin{array}{l}0.50066 \\
2.6253\end{array}$ \\
\hline $\ln \left(\right.$ patent $\left._{t}\right)$ & $\begin{array}{c}0.069393 \\
3.9808\end{array}$ & $\begin{array}{c}0.057499 \\
3.4706\end{array}$ & $\begin{array}{c}0.072610 \\
4.1468\end{array}$ \\
\hline $\ln \left(\right.$ yasam $\left._{t}\right)$ & $\begin{array}{l}3.9306 \\
2.6240\end{array}$ & --- & --- \\
\hline $\ln \left(\right.$ orta $\left._{t}\right)$ & --- & $\begin{array}{c}0.52408 \\
3.0096\end{array}$ & --- \\
\hline $\ln \left(\right.$ yüksek $\left.{ }_{\mathrm{t}}\right)$ & --- & --- & $\begin{array}{l}-0.029872 \\
-0.30036\end{array}$ \\
\hline$E C T_{t-1}$ & $\begin{array}{l}-0.62562 \\
-5.6653 \\
\end{array}$ & $\begin{array}{l}-0.75716 \\
-6.2805 \\
\end{array}$ & $\begin{array}{l}-0.71140 \\
-5.9822 \\
\end{array}$ \\
\hline $\begin{array}{c}\text { Serisel Korelasyon } \\
\text { LM }\end{array}$ & $\operatorname{CHSQ}(1)=1.2432[.265]$ & $\operatorname{CHSQ}(1)=1.9601[.162]$ & $\operatorname{CHSQ}(1)=3.6995[.054]$ \\
\hline $\begin{array}{c}\text { Fonksiyonel Form } \\
\text { LM }\end{array}$ & $\operatorname{CHSQ}(1)=.65956[.417]$ & $\operatorname{CHSQ}(1)=.67593[.411]$ & $\operatorname{CHSQ}(1)=2.2277[.136]$ \\
\hline $\begin{array}{l}\text { Normallik } \\
\text { LM }\end{array}$ & $\operatorname{CHSQ}(2)=4.7017[.095]$ & $\operatorname{CHSQ}(2)=2.8582[.240]$ & $\operatorname{CHSQ}(2)=.31262[.855]$ \\
\hline $\begin{array}{l}\text { Değişen Varyans } \\
\text { LM }\end{array}$ & CHSQ $(1)=3.6821[.055]$ & CHSQ( $(1)=.18226[.669]$ & $\operatorname{CHSQ}(1)=5.6796[.017]$ \\
\hline
\end{tabular}

Uzun dönemli modelin bir dönem gecikmeli hata terimi olan $E C T_{t-1}$ kısa dönemli modellerde istatistiksel olarak anlamlı ve beklendiği gibi 0-1 aralığında ve negatif çıkmıştır. Bu katsayı değişkenler arasında var olan uzun dönem ilişkinin kısa dönemde yapmış olduğu sapmanın hangi hızda düzeltildiğini göstermektedir. Model 1, model 2 ve model 3'de kısa dönem sapmaları sirasıly $\% 63, \% 76$ ve $\% 71$ oranında bir sonraki dönemde düzeltilmektedir.

İnceleme dönemi içerisinde yapısal kırılmalar varsa tahmin edilen katsayılar istikrarlı olmayabilir. Uzun dönem modelin istikrarını kontrol etmek için Brown, Durbin ve Evans (1975) tarafindan geliştirilen CUSUM ve CUSUMQ testleri uygulanmıştır. Şekil 1'de görüldüğ̈̈ gibi grafikler $\% 5$ anlamlılık düzeyinde istenen güven aralığ içinde kalmışlardır. Model 1 ve Model 2'nin CUSUMQ grafiklerinde küçük bir taşma olsa da seri tekrar güven aralığı içine döndüğünden model katsayılarının istikrarını bozmamaktadır. 
Harun YAKIŞIK \& Ahmet ÇETIN

Şekil: 1

Uzun Dönme Modelin CUSUM ve CUSUMQ Grafikleri
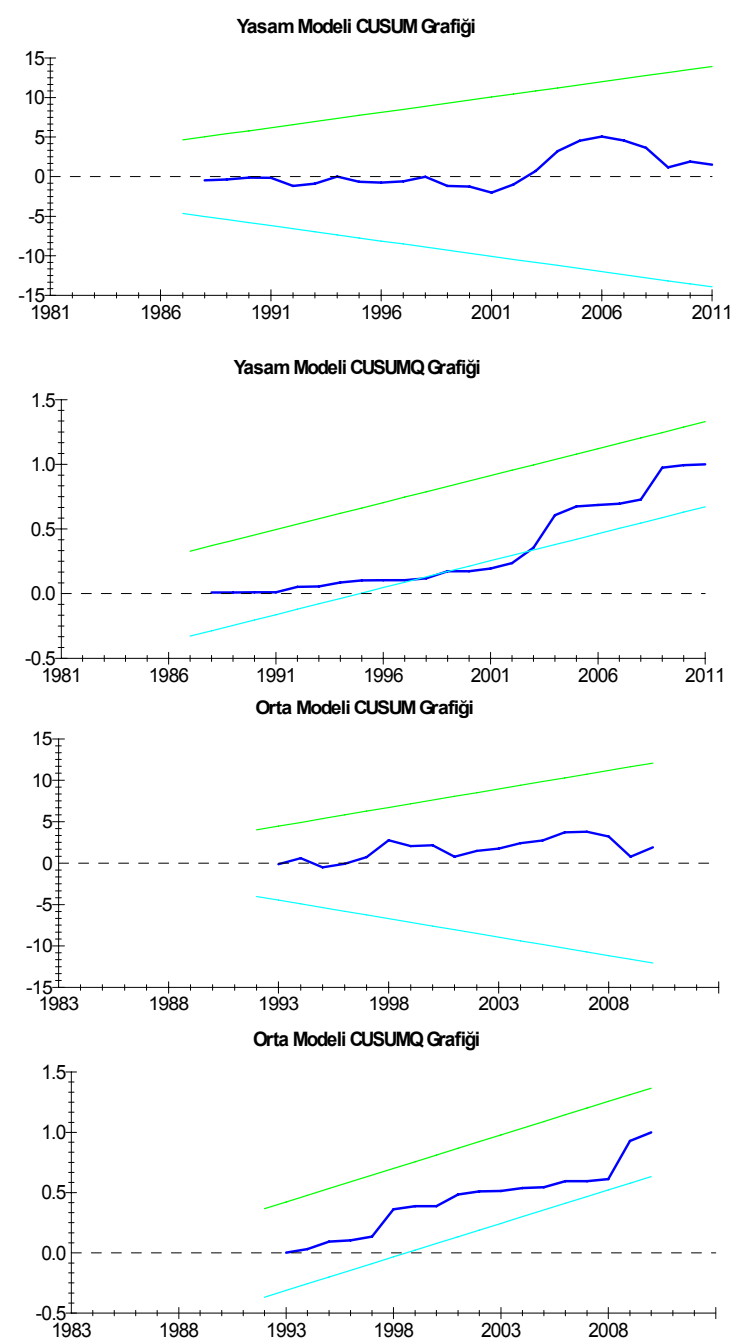


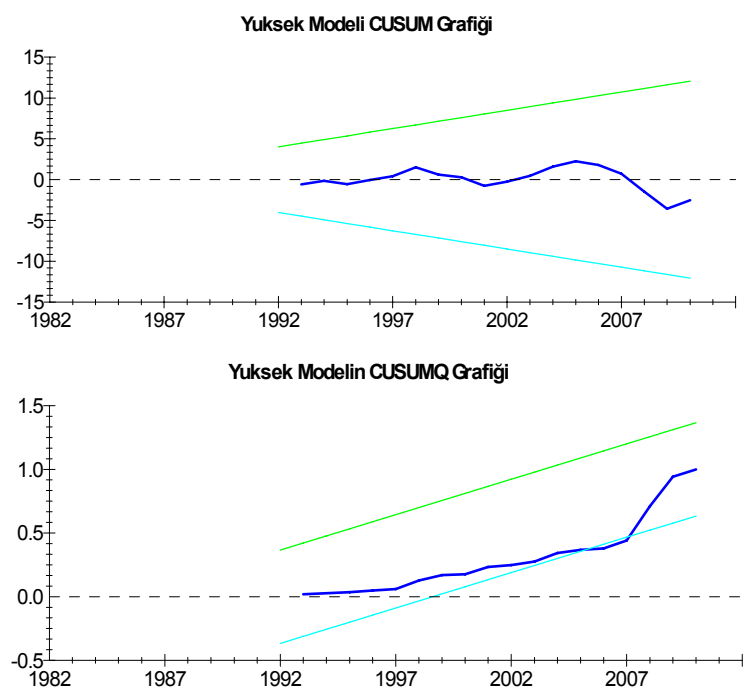

\section{Ampirik Bulguların Değerlendirilmesi}

Bu çalışmada teknoloji değişkeni $A_{t}$ 'nin bağımsız değişken olarak model içinde tutulmak istemesinin nedeni, teknoloji düzeyinin ekonomik büyüme üzerindeki etkisini ölçmektir. $A_{t}$ ve $k_{t}$ tüm modellerde bulunan ortak bağımsız değişkenlerdir. Bulgularda dikkat çeken bir husus, tüm modellerde teknoloji değişkeni $A_{t}$ istatistiksel olarak anlamlı çıkmıştır. Büyüme alanında yapılan çalışmalarda zaman zaman kontrol değişkeni olarak tercih edilecek kadar güçlü bir etkiye sahip olan $k_{t}$, Model 1'de ve Model 2'de anlamsizken sadece Model 3'de anlamlı çıkmıştır. Teknoloji değişkeni $A_{t}$ modele bağımsız değiş̧ken olarak alındığında, sermaye etkisini zayıflattığı, hatta Model 1'de ve Model 2'de sermaye değişkenini anlamsızlaştırdığı görülmektedir. Oysa Türkiye'de teknolojiyi temsil eden patent sayıları OECD ortalamasının çok altında ve Ar-Ge harcamalarının GSYIH içerisindeki payları OECD ve orta-düşük gelirli ülke ortalamalarından bile düşüktür (Kazgan, 2000). Türkiye'nin en büyük ticari partneri olan Avrupa Birliği'ne yapılan ihracatın yapısına baktığımızda, ihracat desenini düşük-orta teknoloji içerikli sektör ürünlerinin oluşturduğunu görmekteyiz. İleri teknoloji içerikli ihracatın payı 2012 yılı itibariyle \% 4,8 seviyelerinde gerçekleşmiştir (Eşiyok, 2013). Bilgi ve teknolojinin geliştirilmesindeki bu zayıf performansa rağmen, $A_{t}$ değişkeninin ekonomik büyümeyi güçlü bir şekilde desteklemesi, politika yapıcısına teknolojinin geliştirilmesi ve desteklenmesi durumunda çok daha yüksek büyüme hızlarına ulaşılabileceği yönünde kanitlar sunmaktadır. 
Modelde beşeri sermayeyi temsil eden ortalama yaşam süresinin anlamlı ve pozitif çıkması, toplumun ve dolayısıyla çalışanların almış olduğu sağlık hizmetleri sonucunda daha sağlıklı ve uzun yaşadıkları ve bunun bir sonucu olarak ekonomik büyümeyi artırdığını göstermektedir. Literatürde özellikle düşük gelirli ülkelerde ortalama yaşam süresi artışının büyüme üzerinde daha büyük etkisinin olduğu (Bhargava vd. 2001) ve ortalama yaşam süresiyle büyüme arasında pozitif ilişki olduğunu gösterir birçok çalışma bulunmaktadır (Croiu ve Licandro, 1999). Türkiye'ye yönelik yapılan çalışmalarda da ortalama yaşam süresiyle büyüme arasında pozitif ilişki bulunmuştur (Taban, 2004).

\section{Sonuç}

Bu çalışmada Türkiye'nin 1980-2012 dönem verileri kullanılarak eğitim, sağlık ve teknolojinin ekonomik büyüme üzerindeki etkisi ARDL yöntemiyle ölçülmeye çalışılmıştır. Çalışmada, Mankiw vd. (1992)'in MRW modeli modifiye edilerek tahmin edilmiştir. MRW modelinde Cobb-Douglas tipi üretim fonksiyonu $A_{t} L_{t}{ }^{\prime}$ ye bölünerek teknoloji değişkeni işgücü ile ilişkilendirilerek denklemde saklanırken, bizim modelimizde denklemin her iki tarafi sadece $L_{t}$ 'ye bölünmüş ve böylece teknoloji değişkeni $A_{t}$ 'nin modelde kalarak büyüme üzerindeki etkisi takip edilebilmiştir. Teknoloji göstergesi olarak patent sayıları ve beşeri sermayeyi temsilen sağlık ve eğitim değişkenleri alternatifli olarak kullanılmıştır. Sağlık değişkeni olarak ortalama yaşam süresi seçilirken eğitim değişkeni olarak orta-öğretim ve yükseköğretim okullaşma oranları alınmıştır.

Elde edilen ampirik bulgulara göre,

(i) teknoloji düzeyini temsil eden patent sayılarının tüm modellerde istatistiksel olarak anlamlı ve ekonomik büyümeyi pozitif yönde etkilediği,

(ii) beşeri sermayeyi sağlık göstergesi olarak temsil eden ortalama yaşam süresinin istatistiksel olarak anlamlı ve ekonomik büyümeyi pozitif yönde etkilediği,

(iii) beşeri sermayeyi eğitim göstergesi olarak temsil eden orta-öğretim okullaşma oranı istatistiksel olarak anlamlı ve ekonomik büyümeyi pozitif yönde etkilediği; ancak yükseköğretim okullaşma oranının istatistiksel olarak anlamsız olduğu sonucuna ulaşılmıştır.

Modelde beşeri sermayeyi temsil eden eğitim değişkenlerinden orta-öğretim okullaşma oranı anlamlı ve pozitif çıkarken, yükseköğretim okullaşma oranı anlamsız bulunmuştur. Eğitim değişkenlerinden orta-öğretim düzeyi anlamlı çıkarken yükseköğretim düzeyinin anlamsız çıkması açılanması gereken bir durumdur. TÜİK 2013 verilerine göre istihdamın \%60'1 ilköğretim düzeyinde eğitimli ve okuma-yazma bilmeyen 
çalışanlar toplamından oluşmaktadır. İşgücü piyasası açısından bakıldığında orta öğretim düzeyi çalışanların \%60'ından daha yüksek bir eğitim kademesine karşılık gelmektedir. Dolayısıyla orta-öğretim okullaşma oranının yükselmesi işgücü piyasasının eğitim düzeyinin yükselmesi anlamına gelmektedir. Yükseköğretim eğitim düzeyi ise işgücü piyasasına göre çok daha yüksek bir eğitim kademesine karşılık gelmektedir. Yükseköğretim okullaşma oranının anlamlı çıkmamasının nedeni, bu eğitim düzeyinin işgücü piyasası ihtiyaçlarından çok daha yüksek bir kademe olmasından kaynaklanabilir. Türkiye'de üretim deseninin tarım sektörüyle düşük-orta düzey teknoloji sektörleri ağırlıklı olduğu düşünülürse, yükseköğretim mezun talebinin yüksek olmayacağı tahmin edilebilir. Bu durumda yükseköğretim mezunlarının artması muhtemelen yükseköğretim gerektirmeyen alanlarda istihdam edilmeleriyle sonuçlanmaktadır. $\mathrm{Bu}$ da, neden yükseköğretim okullaşma oranı ile büyüme arasında ilişki bulunamadığının cevabı olabilir. Türkiye üzerinde yapılan yükseköğretimle pozitif ilişki bulamayan benzer çalışmalar bu bulgumuzu destekler niteliktedir (Deniz ve Doğruel, 2008; Erdoğan ve Yıldırım, 2009).

Yükseköğretim okullaşma oranı ile büyüme arasında pozitif ilişki bulunamaması, daha önemli sorunları beraberinde getirmektedir. Yükseköğretim büyümeyi etkilemiyorsa yükseköğretim okullaşma oranının yükseltilmesi gerekli görünmeyebilir. Oysa bilgi-teknoloji tabanlı ekonomik yapılanma için her eğitim kademesinde yüksekokullaşma oranları ön şart niteliğindedir. $\mathrm{Bu}$ nedenle, gelişmiş ülkelerde zaten yüksek olan yükseköğretim okullaşma oranı, gelişmekte olan ülkelerde de yükseltilmeye çalışılmaktadır. Türkiye örneğinde çelişkili durum çıkmasının nedeni, yükseköğretimde okullaşma oranı çok hızlı yükselirken bu mezunların istihdam edilebilecekleri ileri teknoloji sektörleri aynı hızda gelişememişlerdir. Sonuç olarak yükseköğretim mezunları düşük ve orta düzey teknolojik sektörlerde istihdam edilmek zorunda kalınmış olabilir. Bu varsayımlar altında, Türkiye ekonomisinde düşük-orta düzey teknoloji sektörlerinden yüksek teknoloji sektörlerine yönelmek, hem yükseköğretim mezunlarının büyümeye katkısını sağlayacak hem de zaten pozitif katkısı olan teknoloji değişkeninin büyümeye katkısını yükseltecektir. Fakat bütün bu tespitler bu çalışmamın sınırlarını aşmakta ve yeni bilimsel çalışmalarla desteklenmeye ihtiyaç duymaktadır.

\section{Kaynakça}

Aghion, P. \& P. Howitt (1992), “A Model of Growth through Creative Destruction”, Econometrica 60, 323-351.

Arndt, C. (2006), "HIV/AIDS, Human Capital, and Economic Growth Prospects for Mozambique", Journal of Policy Modeling, 28, 477-489.

Barro R.J. \& Jong-Wha Lee (1998), "Schooling Quality in a Cross Section of Countries", Harvard College Development Discussion Paper, No. 659, October 1998, Boston. 
Becker, Gary (1974), “A Theory of Social Interactions”, Journal of Political Economy, 82(6), 106393.

Beşkaya, A. \& B. Sava \& F. Şamiloğlu (2010), "The Impact of Education on Economic Growth in Turkey”, Süleyman Demirel Üniversitesi İktisadi ve İdari Bilimler Fakültesi Dergisi, Cilt: 15, Say1: 3, 43-62.

Bhargava, A. \& D.T. Jamison \& J. Lawrance \& L. Murray (2001), "Modelling the Effects of Health on Economic Growth," Journal of Health Economics, 20, 423-440.

Bloom, D.E. \& D. Canning (2000), “The Health and Wealth of Nations”, Science, 287, 1207-1209.

Cole, M.A. \& E. Neumayer (2006), "The Impact of Poor Health on Total Factor Productivity”, Journal of Development Studies, 42, 918-938.

Couderc, N. \& B. Ventelou (2005), “AIDS, Economic Growth and the Epidemic Trap in Africa”, Oxford Development Studies, 33, 417-426.

Croiu, D. \& O. Licandro (1999), “Life Expectancy and Endogenous Growth,” Economics Letters, $65,255-263$.

Cyprus, Jenna (2013), <http://digitaljournal.com/article/359451>, 05.12.2013.

Çakmak, E. \& S. Gümüş (2005), “Türkiye'de Beşeri Sermaye ve Ekonomik Büyüme: Ekonometrik Bir Analiz (1960-2002)”, Ankara Üniversitesi SBF Dergisi, Cilt: 60, Say1: 1, 59-72.

Denison E.W. (1962), "Education, Economic Growth and Gaps in Information”, The Journal of Political Economy, LXX(5), 124-128.

Deniz, Z. \& A.S. Dogruel (2008), "Disaggregated Education Data and Growth: Some Facts from Turkey and MENA Countries", Topics in Middle Eastern and North African Economies (electronic journal), 10, <http://www.luc.edu/orgs/meea/volume10/meea10.html>, 25.07.2013.

Domar, E.D. (1946), “Capital Expansion, Rate of Growth, and Employment”, Econometrica, 14, 137-147.

Erdil, E. \& I.H. Yetkiner, “A Panel Data Approach for Income-Health Causality”, $<$ http://www.fnu.zmaw.de/fileadmin/fnu-files/publication/working-papers/FNU47.pdf>, 12.03.2014.

Ergen, H. (1999), “Türkiye’de Eğitimin Ekonomik Büyümeye Katkısı”, Ekonomik Yaklaşım, Cilt: 10, Sayı: 35, 21-56.

Engle, R.F. \& C.W.J. Granger (1987), "Co-integration and error correction: representation, estimation, and testing", Econometrica, 55(2), 251-276.

Erdoğan, S. \& D.Ç. Yıldırım (2009), “Türkiye’de Eğitim-İktisadi Büyüme İlişkisi Üzerine Ekonometrik Bir İnceleme”, Bilgi Ekonomisi ve Yönetimi Dergisi, 4(2), 11-22.

Eşiyok, B.A. (2013), Türkiye-AB Arasında Dış Ticaretin Teknolojik Yapısı Sektörel Analizler, $<$ http://researchturkey.org/>, 01.12.2013. 
Glomm, G. \& B. Ravikumar (1997), "Productive Government Expenditures and Long-run Growth", Journal of Economic Dynamics and Control, 21, 183-204.

Grossman, G. \& E. Helpman (1991), "Quality Ladders in the Theory of Growth”, Review of Economic Studies, 58, 43-61.

Hanushek, E. \& D. Kimko (2000), "Schooling, Labour-force Quality, and the Growth of Nations", American Economic Review, 90, 1184-1208.

Harrod, R. (1939), “An Essay in DynamicTheory”, The Economic Journal, 193, 14-33.

İlgüner, Muhterem (2013), <http://brandfinance.com/>, 02.12.2013.

Johansen, S. \& K. Juselius (1990), "Maximum likelihood estimation and inference on cointegration with applications to the demand for money", Oxf. Bull. Econ. Stat., 52(2), 169-210.

Kar, M. \& H. Ağır (2003), “Türkiye'de Beşeri Sermaye ve Ekonomik Büyüme: Nedensellik Testi”, II. Ulusal Bilgi, Ekonomi ve Yönetim Kongresi, 17-18 May1s, Kocaeli Üniversitesi, Derbent-İzmit.

Kazgan, G. (2000), "Yeni Hükümetin Çözmesi Gereken Ekonomik Sorunlar, Karşılaştığı Olanak ve Kisitlar”, ISO Dergisi, Say1: 310, İstanbul.

Kelly, T. (1997), "Public Expenditures and Growth", Journal of Development Studies, 34(1), 60-84.

Krugman, P. (1994), “The Myth of Asia’s Miracle”, Foreign Affairs, 73, 62-78.

Lucas, R.E. (1988), “On the Mechanics of Economic Development,” Journal of Monetary Economics, 22, 3-42.

Mankiw, N.G. \& D. Romer \& D.N. Weil (1992), "A Contribution to the Empirics of Economic Growth", Quarterly Journal of Economics, 107(2), 407-437.

McDonald, S. \& J. Roberts (2006), “AIDS and Economic Growth: A Human Capital Approach”, Journal of Development Economics, 80, 228-250.

Narayan, P.K. (2005), "The saving and investment nexus for China: evidence from cointegration tests", Applied Economics, 37(17), 1979-1990.

Page, J.M. (1994), “The East Asian Miracle: Four Lessons for Development Policy”, in S. Fischer \& J.J. Rotermberg (Eds.), NBER Macroeconomics Annual 1994, MIT Press, Cambridge, MA.

Pesaran, M. \& Y. Shin (1999), “An autoregressive distributed lag modelling approach to cointegrated analysis", in: S. Strom (Ed.), Econometrics and Economic Theory in the 20th Century, The Ragnar Frisch Centennial Symposium, Cambridge University Press, Cambridge, MA.

Pesaran, M.H. \& Y. Shin \& R.J. Smith (2001), "Bounds testing approaches to the analysis of level relationships", Journal of Applied Econometrics, 16 (3), 289-326.

Psacharopoulos, G. (1981), "Returns to Education: An Updated International Comparison", Comparative Education, 17(3), 321-341. 
Romer, P.M. (1986), “Increasing Returns and Long Run Growth”, Journal of Political Economy, 94(5), 1002-1037.

Romer, P.M. (1990), “Endogenous Technological Change”, Journal of Political Economy, 98, 71102.

Sala-i Martin, X. (1990), "Lecture Notes on Economic Growth (I): Introduction to the Literature and Neo-Classical Models", NBER Working paper, No. 3563.

Saygıll, Ş. \& C. Cihan \& H. Yurtoğlu (2005), Türkiye Ekonomisinde Sermaye Birikimi, Verimlilik ve Büyüme (1972-2003): Uluslararası Karşılaştırma ve AB'ye Yakınsama Süreci (2014), TÜSİAD Büyüme Stratejileri Dizisi, No: 6, Aralık.

Schultz T.W. (1968), "Education and Economic Growth: Return to Education", Readings in the Economics of Education, UNESCO, France, 277.

Schultz, T.P. (1996), “Accounting for Public Eupenditures on Education: An International Panel Study", in T.P. Schultz (Ed.), Research in Population Economics, Vol .8., JAI Press, Greenwich, CT.

Solow, Robert (1956), “A Contribution to the Theory of Economic Growth”, Quarterly Journal of Economics, 70(1), 65-68.

Swan, T.W. (1956), "Economic Growth and Capital Accumulation", Economic Record, 32, 334-361.

Taban, S. (2004), “Türkiye'de Sağlık ve Ekonomik Büyüme İlişkisi: Nedensellik Testi,” 3. Ulusal Bilgi Ekonomi ve Yönetim Kongresi Bildiriler Kitabı, Eskişehir: Osmangazi Üniversitesi Yayınları, No: 108, 3-12.

World Bank (1993), The East Asian miracle, economic growth and public policy, Oxford University Press, New York. 